\title{
Aortic arch aneurysm: 10 years' experience
}

\author{
Radoslaw Gocol ${ }^{1}$, Jaroslaw Bis ${ }^{1}$, Magdalena Piekarska ${ }^{1}$, Damian Hudziak $^{1}$, Łukasz \\ Morkisz $^{1}$, and Marek Deja ${ }^{2}$ \\ ${ }^{1}$ Medical University of Silesia \\ ${ }^{2} \mathrm{GCM}$
}

April 5, 2021

\begin{abstract}
Background Open aortic arch surgery is a complex cardiac surgical procedure. Aims We have reviewed the 10-year outcomes of elective surgery for aortic arch aneurysm in the Cardiac Surgery Department, Upper-Silesian Medical Center of the Medical University of Silesia. Methods The analysis includes all patients who underwent elective aortic arch surgery at our institution from January 2010 to December 2020. To assess the impact of the surgical learning curve the study population was divided into group A consisting of patients operated during the first 5 years, and group B, including patients operated during the subsequent 5 years. Both groups were compared with regard to baseline characteristics, scope of the surgery, operative and postoperative data as well as morbidity and mortality. Results Eighty-six elective aortic arch surgeries were performed during the analyzed period, including 25 patients (29\%) in group A and 61 patients in group B (71\%). The hemiarch procedure was more frequently performed in group A (17 patients, 68\%) in comparison to group B (21 patients, $34 \%)(\mathrm{P}=0.008)$. More procedures on the descending aorta were performed in group B (27 patients, 44\%) than in group A (6 patients, 24\%) $(\mathrm{P}=0.09)$. Stroke was recorded in 6 patients $(20 \%)$ from group $\mathrm{A}$ and 5 patients $(8.2 \%)$ from group $\mathrm{B}(\mathrm{P}=0.002)$. Five-year survival was $60 \pm 9.8 \%$ for group $\mathrm{A}$, and $81 \pm 6.2 \%$ for group $\mathrm{B}$ (log-rank test, $\mathrm{P}=0.003$ ). Conclusions After completion of the learning curve, open aortic arch surgery is associated with acceptable early mortality, low incidence of stroke, and high 5-year survival rate.
\end{abstract}

\section{Aortic arch aneurysm: 10 years' experience}

Radosław Gocol ${ }^{1}$, Jarosław Bis ${ }^{1,2}$, Magdalena Piekarska ${ }^{1,2}$, Damian Hudziak ${ }^{1}$, Lukasz Morkisz ${ }^{1}$, Marek A. Deja $^{1,2}$

${ }^{1}$ Department of Cardiac Surgery, Upper-Silesian Medical Center of the Medical University of Silesia, Katowice, Poland.

${ }^{2}$ Department of Cardiac Surgery, Medical University of Silesia, School of Medicine in Katowice, Poland

\section{Short title: Open aortic arch surgery}

\section{Corresponding author:}

Radosław Gocol MD

Department of Cardiac Surgery,

Medical University of Silesia

ul. Ziołowa $45 / 47$

40-635 Katowice, Poland

e-mail:gocot@poczta.onet.pl 
phone number +48323598644

All authors have no conflict of interest to disclose.

\begin{abstract}
Background

Open aortic arch surgery is a complex cardiac surgical procedure.
\end{abstract}

\title{
Aims
}

We have reviewed the 10-year outcomes of elective surgery for aortic arch aneurysm in the Cardiac Surgery Department, Upper-Silesian Medical Center of the Medical University of Silesia.

\section{Methods}

The analysis includes all patients who underwent elective aortic arch surgery at our institution from January 2010 to December 2020. To assess the impact of the surgical learning curve the study population was divided into group A consisting of patients operated during the first 5 years, and group B, including patients operated during the subsequent 5 years. Both groups were compared with regard to baseline characteristics, scope of the surgery, operative and postoperative data as well as morbidity and mortality.

\section{Results}

Eighty-six elective aortic arch surgeries were performed during the analyzed period, including 25 patients $(29 \%)$ in group A and 61 patients in group B (71\%). The hemiarch procedure was more frequently performed in group A (17 patients, 68\%) in comparison to group B (21 patients, 34\%) $(P=0.008)$. More procedures on the descending aorta were performed in group B (27 patients, 44\%) than in group A (6 patients, 24\%) $(P=0.09)$. Stroke was recorded in 6 patients $(20 \%)$ from group A and 5 patients $(8.2 \%)$ from group B $(P$ $=0.002$ ). Five-year survival was $60 \pm 9.8 \%$ for group A, and $81 \pm 6.2 \%$ for group B (log-rank test, $P=0.003$ ).

\section{Conclusions}

After completion of the learning curve, open aortic arch surgery is associated with acceptable early mortality, low incidence of stroke, and high 5-year survival rate.

\section{Key words}

aortic arch aneurysm, hemiarch replacement, total arch replacement

\section{Introduction}

Isolated aortic arch aneurysm is a condition rarely encountered in cardiac surgery [1]. Usually, aortic arch aneurysms co-exist with the enlargement of adjacent segments of ascending and/or descending aorta (Fig1A). Saccular aneurysms with their limited extent are the exception. Surgical treatment of isolated aortic arch aneurysms, or those co-existing with diseases of other segments of the aorta is complex and technically demanding, particularly when classical surgical techniques (Fig.1A) have to be supplemented with endovascular procedures. As aortic arch surgery requires temporary circulatory arrest, adequate protection of the central nervous system is of paramount importance to avoid complications associated with brain ischemia [2]. Current guidelines recommend elective surgery, when the diameter of the aortic arch measures [?]5.5 cm or this diameter increases at least $0.5 \mathrm{~cm}$ per year. In patients with connective tissue diseases surgery is recommended when the diameter of the aortic arch measures [?] $4.5 \mathrm{~cm}$ or this diameter increases at least 0.2 $\mathrm{cm}$ per year [3].

Aim of this study was to review the 10-year outcomes of elective surgery for aortic arch aneurysm.

\section{Materials and Methods}

The analysis includes all consecutive patients who underwent elective aortic arch aneurysm surgery in the Department of Cardiac Surgery, Upper Silesian Medical Center of the Medical University of Silesia from 
January 2010 until December 2020. Patients were referred for elective surgery according to current guidelines. Following indications for aortic arch surgery were identified: aortic arch aneurysm, chronic aortic dissection, and saccular aneurysm of aortic arch.

Patients with coexisting heart disease, requiring additional surgical procedures, were not excluded. However, excluded were patients with acute type A aortic dissection undergoing emergency surgery.

Primary surgery outcome measure was mortality, ascertained from 1 or more of the following: patient's visit in the outpatient clinic, telephone contact with the patient or patient's relatives, National Registry of Cardiac Surgical Procedures (Krajowy Rejestr Operacji Kardiochirurgicznych) (www.krok.csioz. gov.pl.) Krajowy Rejestr Operacji Kardiochirurgicznych registry contains the mortality data obtained from the National Health Fund (Narodowy Fundusz Zdrowia). Death from all causes was included into the analysis.

The local Institutional Review Board opinion was requested. They decided that the follow-up was not a medical experiment, and therefore, their approval was not required (decision number $\mathrm{KNW} / 0022 / \mathrm{KB} / 284 / 17$ dated 12 December 2017).

To assess the impact of the surgical learning curve the study population was divided into group A consisting of patients operated during the first 5 years, and group B, including patients operated during the subsequent 5 years. Both groups were compared with regard to baseline characteristics, scope of the surgery, operative and postoperative data as well as morbidity and mortality.

\section{Surgical technique}

Surgery was performed via median sternotomy or left lateral thoracotomy. The selection of one of the arterial accesses for cardiopulmonary bypass (CPB) (ascending aorta vs aortic arch vs brachiocephalic trunk vs right or left common carotid artery vs femoral artery) depended on the extent of aneurysm and/or dissection, the planned extent of the repair, as well as the cerebral protection method, and was left to the discretion of the operating surgeon. The right atrium was used for blood drainage for CPB. Depending on the central nervous system protection technique implemented during circulatory arrest, the patient was cooled to 17 degrees $\mathrm{C}$ (deep hypothermic circulatory arrest, DHCA) or 26 degrees $\mathrm{C}$ when selective brain perfusion was used. The patients' body temperature was measured simultaneously in the esophagus and in the bladder. One of the 3 types of cardioplegic regimens was used: cold del Nido cardioplegic solution, cold blood cardioplegic solution (4:1 ratio) and cold miniplegia.

One of the following techniques was used for central nervous system protection:

- deep hypothermic circulatory arrest (DHCA) [4]

- moderate hypothermia with circulatory arrest and selective antegrade cerebral perfusion (SACP) with monitoring of cerebral oxygenation (INVOS 5100C, Medtronic, Dublin, Ireland) [5]

- in surgeries involving the descending aorta the cerebrospinal fluid drainage with monitoring of cerebrospinal fluid pressure was performed [6].

The patients' arterial blood pressure was monitored in both left and right radial arteries and in one of the femoral arteries.

The scope of aortic arch surgeries (open arch surgery):

- Partial replacement of the aortic arch (hemiarch) - involving the replacement of the minor curvature of the aortic arch [7] (Fig. 2A).

- total arch replacement (TAR) involving aortic arch replacement with concomitant re-implantation of arch vessels en-bloc or with separate anastomoses [8] (Fig. 2B-C).

- implantation of a dacron patch into the base of the saccular aneurysm (Fig. 2D).

Distal anastomosis with the descending aorta was performed end-to-end or in case of the co-existing descending aorta aneurysm with the use of the elephant trunk (ET) [9] or frozen elephant trunk (FET) technique 
[10]. The E-vita OPEN PLUS (Jotec Inc., Hechingen, Germany) system was used for the frozen elephant trunk procedures (Figure 1C).

The additional procedures performed on the aorta included:

supracoronary ascending aorta replacement for ascending aorta aneurysm,

aortic root replacement with coronary arteries re-implantation (Bentall de Bono technique) or valve sparing aortic root replacement (David method or Yacoub method) [11] for aortic root aneurysm.

Other concomitant procedures performed included: aortic valve replacement/aortic valve repair [12], mitral valve replacement/mitral valve repair, tricuspid valve repair, coronary artery bypass grafting.

\section{Statistical analysis}

Data are presented as mean (SD) when normally distributed or as median with 25 th and 75 th percentiles (interquartile range [IQR]) when normality assumptions (the Shapiro-Wilk test) were not met. Categorical data are expressed as a number and percentage. Kaplan-Meier time-to-event curves were generated for the entire cohort and the subgroups were compared with the log-rank (Mantel-Cox) test. The five year survival with standard error was estimated for both groups. GraphPad Prism 8.2.0 (GraphPad Software, San Diego, California, United States) was used for all statistical analysis, except the Cox analysis which was done with IBM SPSS Statistics for Windows, version 22 (IBM Corp. Armonk, New York, United States).

\section{Results}

Eighty-six elective aortic arch surgeries were performed during the analyzed period, including 25 patients (29\%) in group A and 61 patients in group B (71\%). The indication for surgery was aortic arch aneurysm in 53 patients (61.5\%), chronic aortic dissection in 30 patients (35\%) and saccular aneurysm in 3 patients (3.5\%). Patients' median age (IQR) was 64 years (54-69), 50 patients (58\%) were male. Median (IQR) EuroScore II was 4.98 (3.01-8.89). Detailed baseline characteristics of the patients is presented in Table 1.

The analysis of baseline characteristics in both study groups revealed that patients in group B were significantly younger than those in group A, 62 years $(53-68)$ vs 67 years $(60-70)(P=0.046)$ and were in higher New York Heart Association (NYHA) classes $(P=0.049)$. Group B included more patients with co-existing descending aorta aneurysm, 27 patients $(44 \%)$ vs 6 patients $(24 \%)(P=0.09)$. Patients in group A had significantly higher serum creatinine concentration (IQR) of $1.02 \mathrm{mg} / \mathrm{dl}(0.79-1.37) \mathrm{vs} 0.82 \mathrm{mg} / \mathrm{dl}(0.7-1.0)$ $(P=0.004)$, and lower left ventricular ejection fraction (LVEF) (IQR) of 50\% (45-60) vs 55\% (50-60)( $P$ $=0.06$ ).

In the entire study population the hemiarch procedure was performed in 38 patients (44\%) and total aortic arch replacement in 48 patients (56\%). Detailed surgical data is presented in Table 2.

The hemiarch procedure was more frequently performed in group A (17 patients, 68\%) in comparison to group B (21 patients, 34\%) $(P=0.008)$ (Fig. 3). More procedures involving descending aorta were performed in group B (27 patients, $44 \%)$ than in group A (6 patients, $24 \%)(P=0.09)$, and 4 patients $(6.6 \%)$ in group B had an aortic valve sparing procedure in comparison to no patient in group A $(P=0.32)$. Deep hypothermia with circulatory arrest was more frequently used for brain protection in group A: 6 patients (24\%) vs 2 patients $(3.3 \%)(P=0.007)$, whereas there were more selective brain perfusions in group B: 59 patients $(96.7 \%)$ vs 21 patients $(84 \%)(P=0.057)$.

Significantly longer CPB time was recorded in group B (IQR): 200 minutes (148-254) vs 163 minutes (125208) $(P=0.03)$.

There were no differences between study groups regarding postoperative data such as bleeding volume, mechanical ventilation time and days of ICU and hospital stay.

The analysis of postoperative morbidity (Table 2) revealed significantly higher rate of stroke in group A: 6 patients $(20 \%)$ vs 5 patients $(8.2 \%)(P=0.002)$. There were no differences between groups with regard 
to the rate of chest re-exploration due to bleeding, acute kidney failure, pneumonia and surgical wound infection.

This analysis includes complete data on mortality from all patients. The median (IQR)

time of follow-up was 32.5 (13.9-56.6) months. Of note, there was higher early mortality (30 days postsurgery) in patients from group A: 5 patients $(20 \%)$ vs 5 patients $(8.2 \%)(P=0.15)$.

Five-year survival estimated from Kaplan-Meier curve was $60+-9.8 \%$ for group A, and $81+-6.2 \%$ for group B (Fig. 4). The comparison of both study groups showed a significant difference in survival (log-rank test, $P$ $=0.03$ ) favoring those operated during the second 5-year period (group B).

\section{Discussion}

Open aortic arch surgery is a complex surgical procedure requiring meticulous planning and strict collaboration of surgical, anesthetic and perfusionist teams. Specifically, in this type of surgery temporary circulatory arrest is key to enable the replacement of the enlarged aortic segment. Consequently, during open aortic arch surgery, protection is required not only for myocardium (as during standard classical cardiac surgery) but also for central nervous system and vital organs. Our analysis shows that patients undergoing aortic arch surgery are older (median 64 years (54-69)) with many co-existing conditions of the heart and the aorta, often implicating the expansion of the scope of planned surgery.

After having analyzed our 10-year outcomes of open aortic arch surgery, we were struck by the high early mortality of $11.6 \%$, significantly higher than the mortality of $5.5 \%$ reported in the literature to date [13]. Therefore, we decided to break up those 10 years into two 5-year periods.

The analysis of the first 5 years (group A) revealed that the early learning curve period is associated with outcomes significantly worse than those reported in literature. Particularly noticeable are early mortality of $20 \%$ and stroke rate of $24 \%$, whereas Thomas et al. [13] report rates of $5.5 \%$ and $5 \%$ respectively after elective surgery. These results can be regarded as even poorer, keeping in mind that in most cases (68\%) the surgery of aortic arch was limited to only partial replacement (hemiarch). In this type of approach Lima et al. [14] report early mortality of $2.9 \%$ and stroke rate of $4.1 \%$. Worse surgical outcomes in group A are reflected by longer ICU stay, longer time of mechanical ventilation and more acute kidney failure and pneumonia in comparison to group B. Another important factor affecting the postoperative outcome was the central nervous system protection, which in as many as $24 \%$ of patients was limited to deep hypothermic circulatory arrest. This translated into high rate of stroke $(24 \%)$.

With experience gained the number of operated patients increased from 25 patients $(29 \%)$ in group A to 61 patients $(71 \%$ ) in group B, and the scope of surgeries became more extended (from $32 \%$ total arch replacements in group A to $66 \%$ in group B). Additionally, descending aorta and aortic root became more frequently addressed. Frozen elephant trunk with the use of the E-vita OPEN PLUS system (Jotec, Hechingen, Germany) became the preferred technique for surgeries involving the descending aorta.

In the second study group, complementary surgical procedures on aortic root (valve sparing aortic root replacement (VSARR)) and aortic valve, even though technically demanding and time consuming, were not avoided. Of note is the rising ratio of repaired aortic valves from $50 \%$ in group A to $79 \%$ in group B. The extending scope of surgery resulted in longer CPB time in group B: 200 minutes vs 163 minutes $(P=0.003)$

Despite the fact that patients in group B underwent more complex aortic arch surgery, had more additional coronary and valvular procedures, and more redo surgeries, the outcomes were significantly better than in group A. The early mortality of $8.2 \%$ is similar to the data reported by Patel et al [15] in his large series of 721 patients, and even better than the early mortality of $15 \%$ reported from another polish center by Hirnle et al [16].

Meticulous central nervous system protection contributed to the reduction of stroke ratio to $1.6 \%$, which is an excellent result, better than the numbers reported by Patel et al. [15] (4.8\%) and Hirnle et al. [16] 
(9\%). This low ratio of stroke is related to the implementation of selective brain perfusion with cerebral oxygenation monitoring in the majority of operated patients (96.7\%), whereas DHCA was used in only 2 patients $(3.3 \%)$.

To summarize it seems that the key factor impacting the outcomes of open aortic arch surgery is the experience of the team, which translates into reproducible results on par with those reported by other surgical teams specializing in the surgery of aortic arch. Estimated 5-year survival of $81 \%$ after open aortic arch surgery makes it a reliable and reproducible cardiac surgical procedure, associated with good long-term outcomes.

\section{Conclusions}

After completion of the learning curve, open aortic arch surgery is associated with acceptable early mortality, low morbidity (low stroke rate in particular), and good long-term survival.

\section{Author contributions}

Radosław Gocoł: Conceptualization; Data curation; Investigation; Methodology; Writing-original draft; Writing-review \& editing. Jarosław Bis: Investigation; Writing-original draft; Writing-review \& editing. Magdalena Piekarska: Data curation; Writing-review \& editing. Damian Hudziak:Writing-review \& editing. Łukasz Morkisz : Visualization; Writing-review \& editing. Marek A. Deja: Conceptualization; Data curation; Formal analysis; Funding acquisition; Investigation; Methodology; Project administration; Resources; Supervision, Statistics.

\section{References}

1. Cardiac Surgery in the Adult, Fourth Edition. The McGraw-Hill Companies, Inc. New York, 2012.

2. Tian DH, Wan B, Bannon PG, et al. A meta-analysis of deep hypothermic circulatory arrest alone versus with adjunctive selective antegrade cerebral perfusion. Ann Cardiothorac Surg. 2013;2:261-270.

3. Erbel R, Aboyans V, Boileau C, et al. 2014 ESC Guidelines on the diagnosis and treatment of aortic diseases. Eur Heart J 2014;35:2873-2926.

4. Ziganshin BA, Elefteriades JA. Deep hypothermic circulatory arrest. Ann Cardiothorac Surg. 2013;2:303315.

5. Leshnower BG, Myung RJ, Kilgo PD, et al. Moderate hypothermia and unilateral selective antegrade cerebral perfusion: a contemporary cerebral protection strategy for aortic arch surgery. Ann Thorac Surg. 2010;90:547-554.

6. Wortmann M, Böckler D, Geisbüsch P. Perioperative cerebrospinal fluid drainage for the prevention of spinal ischemia after endovascular aortic repair. Gefasschirurgie. 2017;22:35-40.

7. MacGillivray TE. How I Teach Hemi-Arch Replacement. Ann Thorac Surg. 2016;101:1251-1254.

8. Minatoya K, Inoue Y, Sasaki H, et al. Total arch replacement using a 4-branched graft with antegrade cerebral perfusion. J Thorac Cardiovasc Surg. 2019;157:1370-1378.

9. Strauch JT, Spielvogel D, Lauten A, et al. Technical advances in total aortic arch replacement. Ann Thorac Surg. 2004;77:581-589; discussion 589-590.

10. Di Bartolomeo R, Pellicciari G, Cefarelli M, et al. Frozen elephant trunk surgery using the E-vita open plus prosthesis. Ann Cardiothorac Surg 2013;2:656-659.

11. Gocoł R, Malinowski M, Bis J, et al. Aneurysm of the aortic root and valve-sparing aortic root replacement: long-term outcomes from a single Polish center. Kardiol Pol. 2020; 78: 1235-1242.

12. Gocoł R, Malinowski M, Bis J, et al. Long-term outcomes of aortic valve repair in over 500 consecutive patients: a single-center experience. Kardiol Pol. 2020; 78: 861-868. 
13. Thomas M, Li Z, Cook DJ, et al. Contemporary results of open aortic arch surgery. J Thorac Cardiovasc Surg 2012; 144: 838-844.

14. Lima B, Williams JB, Bhattacharya SD, et al. Results of proximal arch replacement using deep hypothermia for circulatory arrest: is moderate hypothermia really justifiable? Am Surg. 2011;77:1438-1444.

15. Patel HJ, Nguyen C, Diener AC, et al. Open arch reconstruction in the endovascular era: analysis of 721 patients over 17 years. J Thorac Cardiovasc Surg. 2011;141:1417-1423.

16. Hirnle T, Stankiewicz A, Matlak K et al. Single-centre experience in surgery of acute aortic type A dissection and true aortic arch aneurysm. Kardiol Pol, 2016; 74: 994-1001.

Table 1. Demographic data.

\begin{tabular}{|c|c|c|c|c|}
\hline Variable & Value & Value & Value & $P$ value \\
\hline & All $(n=86)$ & $\begin{array}{l}\text { Group A } \\
(n=25)\end{array}$ & $\begin{array}{l}\text { Group B } \\
(n=61)\end{array}$ & \\
\hline Male sex & $50(58)$ & $17(68)$ & $33(54)$ & 0.34 \\
\hline $\begin{array}{l}\text { Age [years], } \\
\text { median(IQR) }\end{array}$ & $64(54-69)$ & $67(60-71)$ & $62(53-68)$ & 0.046 \\
\hline $\begin{array}{l}\text { NYHA class NYHA } \\
\text { I } \\
\text { NYHA II } \\
\text { NYHA III } \\
\text { NYHA IV }\end{array}$ & $\begin{array}{l}27(31) 46(54) 10 \\
(12) 3(3.5)\end{array}$ & $\begin{array}{l}7(28) 13(52) 2 \\
(8.0) 3(12)\end{array}$ & $\begin{array}{l}20(33) 33(54) 8 \\
(13) 0\end{array}$ & 0.049 \\
\hline $\begin{array}{l}\text { Previous cardiac } \\
\text { surgery }\end{array}$ & $15(17)$ & $3(12)$ & $12(20)$ & 0.54 \\
\hline $\begin{array}{l}\text { Chronic aortic } \\
\text { dissection }\end{array}$ & $30(35)$ & $11(44)$ & $19(31)$ & 0.32 \\
\hline $\begin{array}{l}\text { Aortic root } \\
\text { aneurysm }\end{array}$ & $13(15)$ & $2(8.0)$ & $11(18)$ & 0.33 \\
\hline $\begin{array}{l}\text { Ascending aorta } \\
\text { aneurysm }\end{array}$ & $70(81)$ & $21(84)$ & $49(80)$ & 0.77 \\
\hline $\begin{array}{l}\text { Descending aorta } \\
\text { aneurysm }\end{array}$ & $33(38)$ & $6(24)$ & $27(44)$ & 0.09 \\
\hline $\begin{array}{l}\text { Saccular aortic } \\
\text { arch aneurysm }\end{array}$ & $3(3.5)$ & $2(8.0)$ & $1(1.6)$ & 0.20 \\
\hline $\begin{array}{l}\text { Arterial } \\
\text { hypertension }\end{array}$ & $65(78)$ & $20(90.9)$ & $45(74)$ & 0.13 \\
\hline $\begin{array}{l}\text { Coronary artery } \\
\text { disease }\end{array}$ & $18(21)$ & $6(24)$ & $12(20)$ & 0.77 \\
\hline $\begin{array}{l}\text { Mitral valve } \\
\text { regurgitation No } \\
\text { Trace Mild } \\
\text { Moderate Severe }\end{array}$ & $\begin{array}{l}(\mathrm{n}=68) 12(18) 26 \\
(38) 19(28) 7(10) 4 \\
(5.9)\end{array}$ & $\begin{array}{l}(\mathrm{n}=7) 05(71) 1 \\
(14) 01(14)\end{array}$ & $\begin{array}{l}(\mathrm{n}=61) 12(20) 21 \\
(34) 18(30) 7(12) 3 \\
(4.9)\end{array}$ & 0.21 \\
\hline $\begin{array}{l}\text { Tricuspid valve } \\
\text { regurgitation No } \\
\text { Trace Mild }\end{array}$ & $\begin{array}{l}(\mathrm{n}=68) 22(32) 19 \\
(28) 19(28) 6(8.8) \\
2(2.9)\end{array}$ & $\begin{array}{l}(\mathrm{n}=7) 2(29) 3(43) \\
1(14) 1(14) 0\end{array}$ & $\begin{array}{l}(\mathrm{n}=61) 20(33) 16 \\
(26) 18(30) 5(8.2) \\
2(3.3)\end{array}$ & 0.80 \\
\hline
\end{tabular}




\begin{tabular}{|c|c|c|c|c|}
\hline Variable & Value & Value & Value & $P$ value \\
\hline $\begin{array}{l}\text { Renal function } \\
\text { Normal } \\
(\text { GFR }>85 \mathrm{ml} / \mathrm{min} / \\
\text { Moderately } \\
\text { impaired [GFR } 50 \\
85 \mathrm{ml} / \mathrm{min} / 1.73 \mathrm{~m} 2 \\
\text { Severely impaired } \\
{[\text { GFR }<35 \mathrm{ml} / \mathrm{min} /} \\
\text { Dialysis }\end{array}$ & $\begin{array}{l}50(58) 28(33) 7 \\
(8.1) 1(1.2) \\
\mathrm{m} 2) \\
\mathrm{m} 2]\end{array}$ & $\begin{array}{l}12(48) 8(32) 4(16) \\
1(4.0)\end{array}$ & $\begin{array}{l}38(62) 20(33) 3 \\
(4.9) 0\end{array}$ & 0.13 \\
\hline Diabetes $(\mathrm{n}=83)$ & $9(11)$ & $4(18)(\mathrm{n}=22)$ & $5(8.2) \quad(\mathrm{n}=61)$ & 0.24 \\
\hline $\begin{array}{l}\text { BMI }\left[\mathrm{kg} / \mathrm{m}^{2}\right] \\
\text { median(IQR) }\end{array}$ & $27(24-30)$ & $28(25-30)$ & $26(24-30)$ & 0.25 \\
\hline $\begin{array}{l}\text { Serum creatinine } \\
{[\mathrm{mg} / \mathrm{dl}],} \\
\text { median(IQR) }\end{array}$ & $0.87(0.74-1.08)$ & $1.02(0.79-1.37)$ & $0.82(0.70-1.00)$ & 0.004 \\
\hline $\begin{array}{l}\text { EF [\%], median } \\
(\mathrm{IQR}),(\mathrm{n}=85)\end{array}$ & $55(50-60)$ & $50(45-60)$ & $55(50-60)$ & 0.06 \\
\hline $\begin{array}{l}\text { EUROSCORE II, } \\
\text { median (IQR) }\end{array}$ & $4.98(3.01-8.89)$ & $4.29(2.82-8.39)$ & $5.34(3.23-9.15)$ & 0.42 \\
\hline
\end{tabular}

Data are presented as number (percentage) of patients unless otherwise indicated.

BMI - body mass index, EF - ejection fraction, NYHA - New York Heart Association

Table 2. Surgery scope, data, complications

\begin{tabular}{|c|c|c|c|c|}
\hline Variable & Value & Value & Value & \\
\hline & All $(n=86)$ & Group A $(n=25)$ & Group B $(n=61)$ & $P$ value \\
\hline $\begin{array}{l}\text { Total aortic arch } \\
\text { replacement: Island } \\
\text { technique Separate } \\
\text { arch vessels } \\
\text { anastomoses }\end{array}$ & $\begin{array}{l}48(56) 23(48) 25 \\
(52)\end{array}$ & $8(32) 5(63) 3(37)$ & $\begin{array}{l}40(66) 18(45) 22 \\
(55)\end{array}$ & 0.45 \\
\hline $\begin{array}{l}\text { Hemiarch } \\
\text { replacement }\end{array}$ & $38(44)$ & $17(68)$ & $21(34)$ & 0.008 \\
\hline VSARR & $4(4.7)$ & 0 & $4(6.6)$ & 0.32 \\
\hline $\begin{array}{l}\text { Bentall de Bono } \\
\text { procedure }\end{array}$ & $3(3.5)$ & $2(8.0)$ & $1(1.6)$ & 0.20 \\
\hline $\begin{array}{l}\text { Ascending aorta } \\
\text { replacement }\end{array}$ & $70(81)$ & $21(84)$ & $49(80)$ & 0.77 \\
\hline $\begin{array}{l}\text { Descending aorta } \\
\text { replacement FET }\end{array}$ & $33(38) 25(29)$ & $6(24) 5(20)$ & $27(44) 20(33)$ & 0.090 .30 \\
\hline $\begin{array}{l}\text { AVR/AVrepair - AV } \\
\text { repair }\end{array}$ & $48(56)$ & $14(56) 7 / 14(50)$ & $34(38) 27 / 34(79)$ & 0.980 .042 \\
\hline MVR/MVrepair & $5(5.8)$ & $1(4.0)$ & $4(6.6)$ & 0.65 \\
\hline TVrepair & $4(4.7)$ & 0 & $4(6.6)$ & 0.32 \\
\hline CABG & $19(22)$ & $5(20)$ & $14(23)$ & 0.99 \\
\hline
\end{tabular}




\begin{tabular}{|c|c|c|c|c|}
\hline Variable & Value & Value & Value & \\
\hline $\begin{array}{l}\text { Canniulation site: } \\
\text { Ascending } \\
\text { aorta/arch } \\
\text { Brachiocephalic } \\
\text { trunk Left common } \\
\text { carotid artery Right } \\
\text { common carotid } \\
\text { artery Femoral } \\
\text { artery }\end{array}$ & $\begin{array}{l}9(10) 56(65) 6 \\
(7.0) 7(8.1) 6(7.0)\end{array}$ & $\begin{array}{l}5(20) 10(40) 3(12) \\
3(12) 3(12)\end{array}$ & $\begin{array}{l}4(6.6) 46(75) 3 \\
(4.9) 4(6.6) 3(4.9)\end{array}$ & 0.07 \\
\hline $\begin{array}{l}\mathrm{CPB} \text { temperature } \\
{\left[{ }^{\circ} \mathrm{C}\right], \text { median }} \\
(\mathrm{IQR})\end{array}$ & $26.75(26-28)$ & $28(26-28)$ & $26(26-28)$ & 0.65 \\
\hline SACP & $80(93)$ & $21(84)$ & $59(96.7)$ & 0.057 \\
\hline $\begin{array}{l}\text { SACP time [min], } \\
\text { median (IQR) }\end{array}$ & $35(21.25-54)$ & $35(20.5-41)$ & $35(22-55)$ & 0.56 \\
\hline $\mathrm{DHCA}$ & $8(9.3)$ & $6(24)$ & $2(3.3)$ & 0.007 \\
\hline $\begin{array}{l}\text { DHCA time } \\
{[\text { min], median }} \\
\text { (IQR) }\end{array}$ & $21(15.5-27.25)$ & $18.5(12.25-25.75)$ & $31.0(22.0-40.0)$ & 0.18 \\
\hline $\begin{array}{l}\text { X-clamp } \\
\text { time[min], median } \\
\text { (IQR) }\end{array}$ & $87(65-114)$ & $86(66-107)$ & $87(64-117)$ & 0.79 \\
\hline $\begin{array}{l}\text { CPB time[min], } \\
\text { median(IQR) }\end{array}$ & $190(139-232)$ & $163(125-208)$ & $200(148-254)$ & 0.03 \\
\hline $\begin{array}{l}\text { Drainage [ml], } \\
\text { median(IQR) }\end{array}$ & $780(560-1143)$ & $800(555-985)$ & $760(600-1190)$ & 0.63 \\
\hline $\begin{array}{l}\text { Ventilation time } \\
{[\mathrm{h}], \text { median }(\mathrm{IQR})}\end{array}$ & $21.2(15.1-43.0)$ & $23.7(16.0-70.1)$ & $20.7(14.8-30.6)$ & 0.18 \\
\hline $\begin{array}{l}\text { ICU stay [days], } \\
\text { median(IQR) } \\
(\mathrm{n}=68)\end{array}$ & $4(2-6)$ & $6(3-6)(\mathrm{n}=7)$ & $4(2-6)$ & 0.36 \\
\hline $\begin{array}{l}\text { Hospital stay } \\
\text { [days], } \\
\text { median(IQR) }\end{array}$ & $9(8-14.25)$ & $8(7-14.5)$ & $9(8-14.5)$ & 0.31 \\
\hline Early death & $10(11.6)$ & $5(20)$ & $5(8.2)$ & 0.15 \\
\hline $\begin{array}{l}\text { Resternotomy for } \\
\text { bleeding }\end{array}$ & $17(20)$ & $5(20)$ & $12(20)$ & 0.97 \\
\hline Stroke & $7(8.1)$ & $6(24)$ & $1(1.6)$ & 0.002 \\
\hline $\begin{array}{l}\text { Renal } \\
\text { failure/hemofiltration }\end{array}$ & $2(2.3)$ & $1(4.0 \%)$ & $1(1.6)$ & 0.50 \\
\hline Pneumonia & $7(8.1)$ & $3(12)$ & $4(6.6)$ & 0.41 \\
\hline Wound infection & $2(2.3)$ & 0 & $2(3.3)$ & 0.90 \\
\hline
\end{tabular}

Data are presented as number (percentage) of patients unless otherwise indicated.

AV - aortic valve, AVR - aortic valve replacement, CABG - coronary artery bypass grafting, CPB - cardiopulmonary bypass, DHCA - deep hypothermic circulatory arrest, ICU - intensive care unit, IQR - interquartile range, MV - mitral valve, MV - mitral valve replacement, SACP - selective antegrade cerebral perfusion, TV - tricuspid valve, VSARR - valve sparing aortic root replacement 


\section{Figure legends}

Figure 1. Aortic arch aneurysm.

A - computerized tomography angiography of the thoracic aorta with aortic arch aneurysm, B - total arch replacement involving aortic arch replacement with concomitant re-implantation of arch vessels

Figure 2. Open aortic arch surgery.

A - hemiarch technique, B - total arch replacement, separate arch vessels anastomoses, C - total arch replacement with FET (Frozen Elephant Trunk, Evita Open System), D - Dacron patch

Figure 3. Comparison of hemiarch and total arch replacement in group's A and B.

Figure 4. Kaplan-Meier survival curves with 95\% CI.

The subgroups were compared with the log-rank (Mantel-Cox) test.

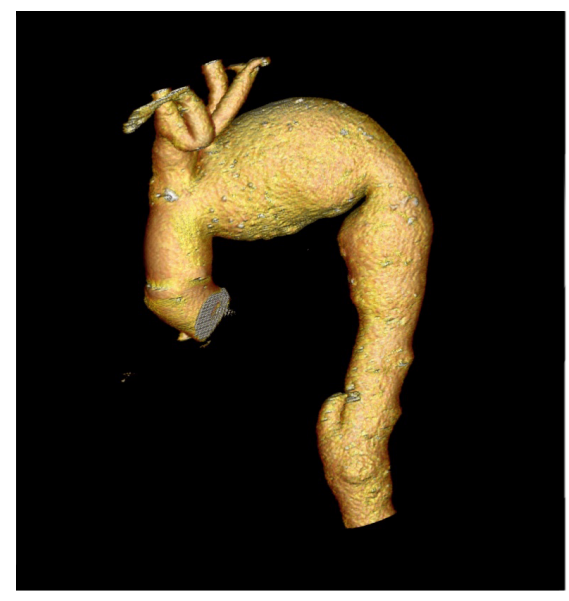

A

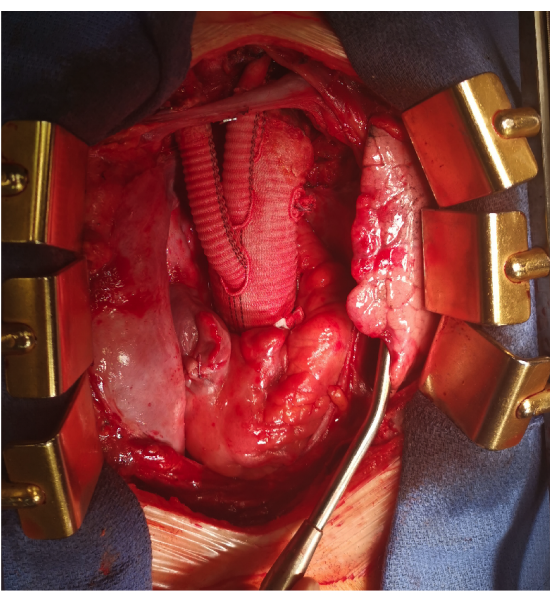

B

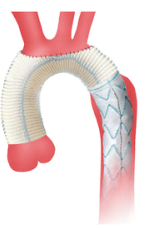

C

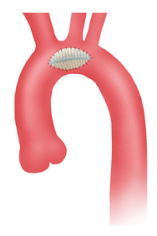

D 

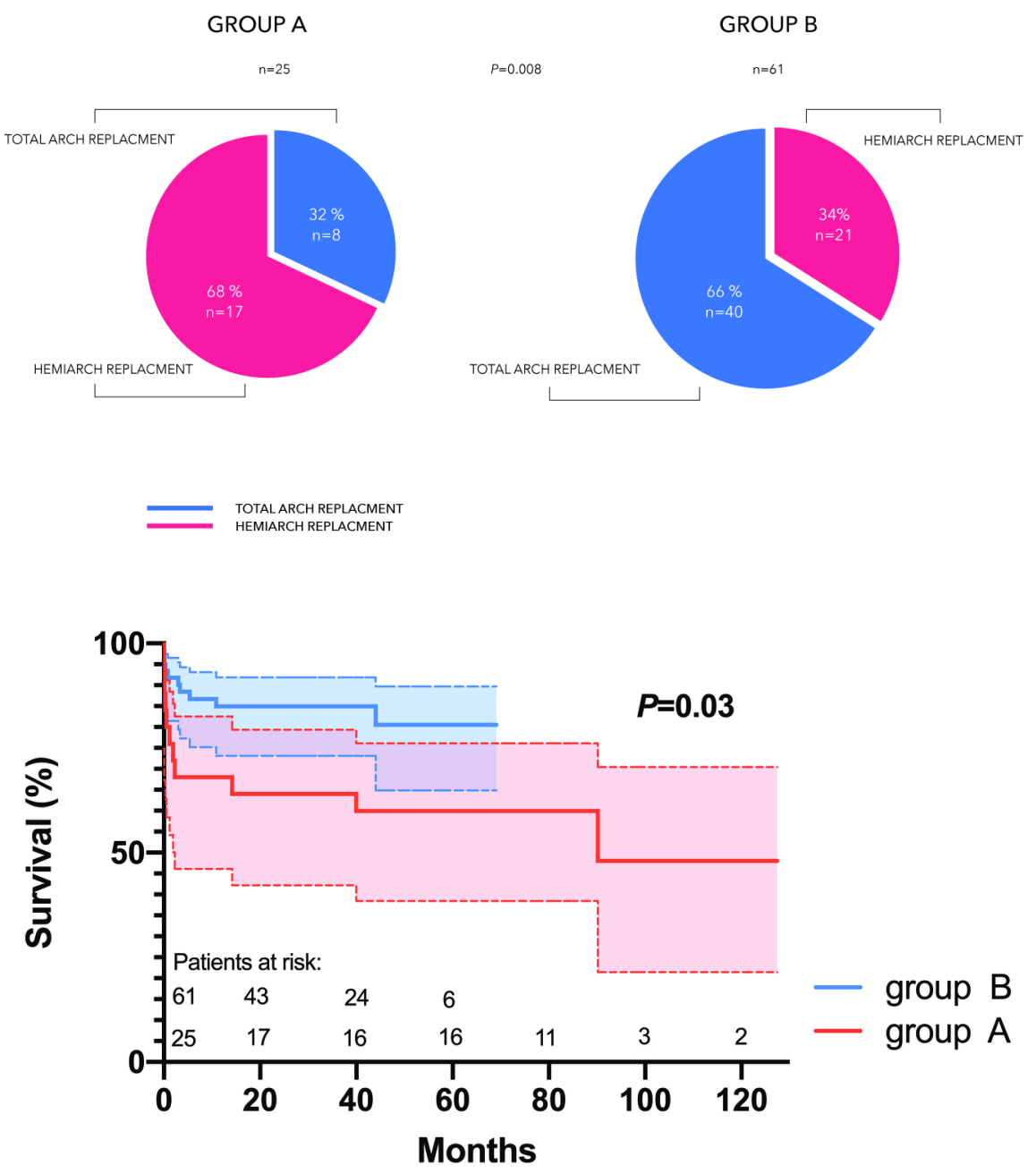